\title{
Структурные особенности текстурированных пленок оксида цинка, полученных методом ионного распыления
}

\author{
() В.Г. Костишин ${ }^{1}$, А.Ю. Миронович ${ }^{1}$, А.В. Тимофреев $^{1}$, И.М. Исаев ${ }^{1}$, Р.И. Шакирзянов ${ }^{1}$, \\ А.И. Риль ${ }^{2}$, А.А. Сергиенко ${ }^{1}$ \\ ${ }^{1}$ Национальный исследовательский технологический университет „МИСиС“, \\ 119049 Москва, Россия \\ ${ }^{2}$ Институт общей и неорганической химии им. Н.С. Курнакова Российской академии наук, \\ 119991 Москва, Россия \\ E-mail: drvgkostishyn@mail.ru
}

Поступила в Редакцию 26 октября 2020 г.

В окончательной редакции 30 октября 2020 г.

Принята к публикации 30 октября 2020 г.

\begin{abstract}
Исследовались текстурированные пленки $\mathrm{ZnO}$, полученные на аморфных подложках методом ионнолучевого распыления. Методами рентгеновской дифракции и атомно-силовой микроскопии показано, что полученные пленки обладают поликристаллической структурой сразу после напыления. Установлено, что при дальнейшем отжиге исследуемых образцов в интервале температур от 200 до $500^{\circ} \mathrm{C}$ происходит рекристаллизация, приводящая к изменению размера зерен и шероховатости поверхности. Обнаружена зависимость интенсивности кристаллизации от условий напыления, которая связана с количеством дефектов в неотожженных пленках. В пленках с изначально более совершенной структурой температурная обработка при $500^{\circ} \mathrm{C}$ привела к росту зерен более чем в 2 раза и уменьшению шероховатости на $\sim 40 \%$.
\end{abstract}

Ключевые слова: оксид цинка, тонкие пленки, кристаллографическая текстура, отжиг, нанесение пленок ионно-лучевым распылением мишени, атомно-силовая микроскопия, рентгеновская дифрактометрия.

DOI: $10.21883 /$ FTP.2021.03.50600.9542

\section{1. Введение}

Оксид цинка $\mathrm{ZnO}$ и его пленки, как материалы электроники, в основном находят свое применение в различных оптических устройствах ультрафиолетового диапазона [1]. Но существуют и альтернативные практические приложения. Помимо непосредственного использования в приборах, анизотропные пленки $\mathrm{ZnO}$ (001) могут применяться в качестве буферных слоев для пленок других материалов, например гексагональных ферритов $\mathrm{BaFe}_{12} \mathrm{O}_{19}$ (001) [2,3]. Несмотря на принадлежность к различным пространственным группам симметрии, текстурированный рост гексаферрита на окиси цинка обусловливается общностью структуры их кислородных плоскостей. Кроме того, эти плоскости образуют гексагональную плотную упаковку, поэтому зародыши $\mathrm{ZnO}$ с ориентацией (001) обладают минимальной поверхностной энергией [4], что увеличивает вероятность их образования и открывает возможность получения текстурированной пленки на аморфных подложках. Данное утверждение имеет под собой не только теоретические обоснования, но и непосредственно подтверждается результатами экспериментов [5,6]. Схема „аморфная подложка-спонтанное образование (001) ZnO-псевдоморфный рост (001) гексаферрита“ представляется экономически более выгодным решением, чем классическая структура „монокристаллическая подложка/пленка“. Такой подход был реализован в работе [7], где изготавливались пленки $\mathrm{BaFe}_{12} \mathrm{O}_{19}(001) / \mathrm{ZnO}(001) /$ плавленый кварц.
Подобное применение анизотропных пленок $\mathrm{ZnO}$ накладывает особые требования к их структуре. Важно получать пленки с наилучшей степенью текстуры, поскольку отклонение в ориентации буферного слоя наследуется функциональным покрытием, в результате чего параметры синтезируемого материала отличаются от ожидаемых. К аналогичным последствиям приводит высокая шероховатость буферного слоя, поскольку зародышеобразование может происходить на боковых гранях выступающих элементов рельефа, что вызовет появление кристаллитов нежелательной ориентации. На шероховатость оказывают влияние различные факторы, в частности условия отжига. Отжиг пленок $\mathrm{ZnO}$ проводится для улучшения кристалличности и аннигиляции кислородных вакансий. Температура отжига в различных работах варьируется от 350 до $900^{\circ} \mathrm{C}$ [5,6,8-12]. Наличие такого разброса по температуре, а также расстановка акцентов на температурные зависимости непосредственно функциональных свойств $\mathrm{ZnO}$ не позволяют по литературным данным однозначно определить оптимальные условия для изготовления анизотропных пленок, качественно отличающихся именно совершенством текстуры. Конечно, работы, сфокусированные на изучении структурных характеристик пленок $\mathrm{ZnO}$, существуют [13]. С другой стороны, таких публикаций немного, вследствие чего целесообразно проводить подобные исследования с применением альтернативных условий синтеза, которые могут повлиять на результаты.

Данное исследование ставит своей целью изучить влияние температуры отжига на особенности кристал- 
лической структуры и микрорельефа текстурированных пленок $\mathrm{ZnO}$, полученных на окисленных кремниевых подложках методом ионно-лучевого распыления.

\section{2. Эксперимент}

В качестве подложек использовались термически окисленные пластины кремния с ориентацией (111). Окисление проводилось при температуре $1050^{\circ} \mathrm{C}$ в атмосфере азота и кислорода. Пленки $\mathrm{ZnO}$ наносились методом ионно-лучевого распыления мишени, изготовленной прессованием порошка $\mathrm{ZnO}$ класса чистый для анализа (ЧДА). Подложки отмывались в течение 5 мин в метилпирролидоне с применением ультразвуковой ванны. Процесс напыления производился в вакуумной камере установки УВН-71-3М в течение 7 мин. Перед нанесением пленок для удаления влаги и обезгаживания подложки прогревались до $300^{\circ} \mathrm{C}$ и выдерживались при этой температуре в течение 10 мин при остаточном давлении $(0.5-1) \cdot 10^{-2}$ Па. Непосредственно нанесение проводилось без нагрева после остывания подложек до комнатной температуры. Расстояние от мишени до подложки составляло 25, 40 и 45 мм. Ток разряда составлял 40-50мA, напряжение разряда - 2-2.1 кВ, давление рабочего газа Ar во время процесса поддерживалось на уровне $4.5-5 \cdot 10^{-2}$ Па. Полученные пленки отжигались на воздухе при температурах 100, 200, 350 и $500^{\circ} \mathrm{C}$ в течение 1 ч. Толщина полученных пленок измерялась на контактном профилометре DekTak 150. Рентгеновские дифрактограммы (РД) получали на дифрактометре BRUKER D8 ADVANCE (CuK $K_{\alpha}$-излучение, $\lambda=0.154 \mathrm{нм}, U=40 \mathrm{\kappa B}, I=40 \mathrm{MA})$. Съемку производили с шагом $0.02^{\circ}$ в диапазоне $2 \theta: 15-100^{\circ}$. При обработке РД использовалась база порошковых дифрактометрических данных ICDD PDF-2 и программные среды Diffrac.SuiteEVA. Снимки атомно-силовой микроскопии (ACM) получали на сканирующем зондовом микроскопе NT-MDT NTEGRA Prima.

\section{3. Результаты и обсуждение}

Первая серия образцов была получена при расстоянии мишень-подложка 25 мм. Толщина всех пленок по данным профилометрии составила $0.2 \pm 0.01$ мкм, что подтверждает стабильность процесса нанесения.

Рентгеновские дифрактограммы данных образцов представлены на рис. 1. Отображаемый диапазон значений $2 \Theta 25-35^{\circ}$ полностью отражает все изменения, наблюдаемые в пленках. Помимо интенсивного пика кремния (111) на всех РД присутствует множество других рефлексов. Как видно из рис. 1, $a$, практически все эти пики относятся к подложке и, вероятно, отражают наличие кристаллических включений $\mathrm{SiO}_{2}$. Хотя в производственной среде считается, что термически окисленный кремний является аморфным, в ряде научных работ указывается возможность образования кристаллического
$\mathrm{SiO}_{2}[14,15]$. В любом случае, выяснение природы этих рефлексов выходит за рамки данного исследования. Что касается непосредственно пленок, то на всех РД можно выделить пик $\sim 34-35^{\circ}$, идентифицируемый как $\mathrm{ZnO}$ (002). Такой результат свидетельствует о том, что кристаллизация пленки протекает непосредственно во время нанесения. Однако следует заметить, что форма пика существенным образом изменяется при отжиге от $200^{\circ}$ С. Уменьшение ширины пика может быть признаком протекания рекристаллизации и сопутствующего улучшения кристаллографической текстуры. Важно, что после отжига не появляется каких-либо дополнительных рефлексов $\mathrm{ZnO}$, свидетельствующих об образовании существенного количества зерен другой кристаллографической ориентации.

На рис. 2 представлена эволюция топографии поверхности полученных пленок $\mathrm{ZnO}$ при отжиге до $500^{\circ} \mathrm{C}$. В целом, результаты АCM хорошо согласуются с данными дифракционного анализа. Так, у всех пленок, в том числе у не подвергавшихся температурной обработке, обнаруживаются округлые зерна, характерные для текстуры (001) [16,17], что подтверждает образование кристаллической фазы ZnO в процессе нанесения. Отжиг при $100^{\circ} \mathrm{C}$ не приводит к заметным преобразованиям микроструктуры, а все существенные изменения происходят при более высоких температурах. После отжига при 200 и $350^{\circ} \mathrm{C}$ в пленках появляются довольно крупные ( 1 мкм) включения, приводящие к резкому росту шероховатости. Можно заметить, что эти включения представляют собой агломерации мелких зерен с плохо выраженными границами. В то же время после отжига при $500^{\circ} \mathrm{C}$ подобных образований не наблюдается, а топография поверхности имеет больше сходства с пленкой, которая не подвергалась термической обработке. Однако в среднем размер зерен образца, отожженного при $500^{\circ} \mathrm{C}$, больше, чем у неотожженной пленки.

Из полученных результатов можно однозначно заключить, что во время отжига при $200^{\circ} \mathrm{C}$ (а также при $350^{\circ} \mathrm{C}$ ) рекристаллизация $\mathrm{ZnO}$ проходит локально. Иными словами, рост и агломерация одних кристаллитов требует значительно меньше энергии, чем других. Такую „неоднородность“ можно объяснить различной ориентацией зерен относительно друг друга в направлениях типа $[h k 0]$. В плоскости аморфной подложки довольно трудно выделить какое-то предпочтительное для роста направление. В связи с этим плоскости кристаллитов $(h k 0)$, перпендикулярные поверхности пленки, могут быть ориентированы произвольным образом. Из-за этого величина угла между плоскостями $(h k 0)$ двух соседних зерен может отличаться для разных пар кристаллитов (рис. 3). Коалесценция соприкасающихся зерен будет проходить тем легче, чем меньше угол разориентировки между граничными плоскостями. В связи с этим при относительно низких температурах может наблюдаться рост и агломерация кристаллитов, разориентированных только на относительно малые углы. По-видимому, для $\mathrm{ZnO}$ при росте температуры отжига до $500^{\circ} \mathrm{C}$ это 

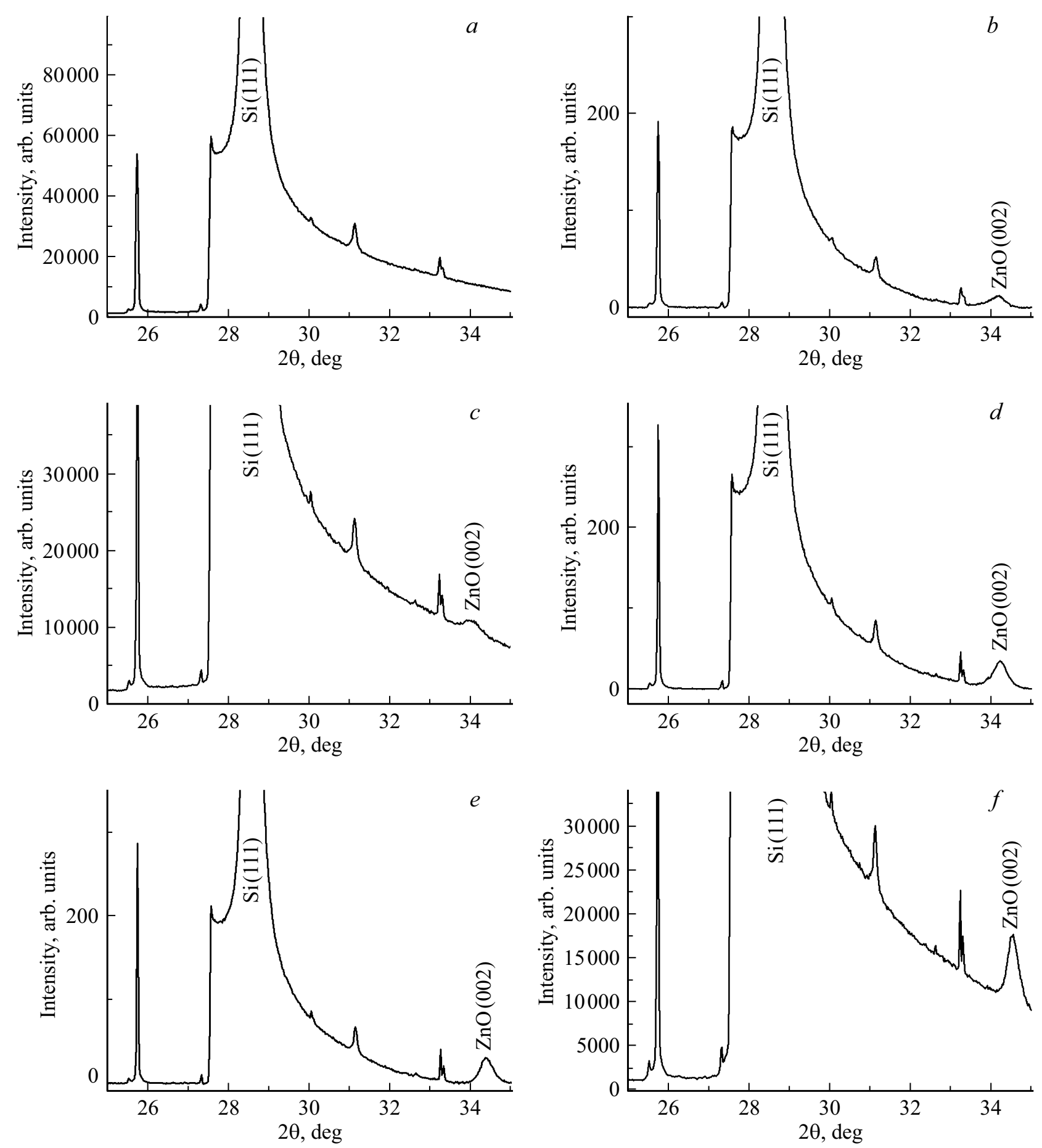

Рис. 1. Рентгеновские дифрактограммы пленок $\mathrm{ZnO}$ на подложке $\mathrm{SiO}_{2} / \mathrm{Si}: a-$ подложка $\mathrm{SiO}_{2} / \mathrm{Si}$ без пленки $\mathrm{ZnO} ; b-$ пленка $\mathrm{ZnO}$ на подложке $\mathrm{SiO}_{2} / \mathrm{Si}$ без термической обработки; пленка $\mathrm{ZnO}$ на подложке $\mathrm{SiO}_{2} / \mathrm{Si}$ после отжига при $100(c), 200(d), 350(e)$, $500^{\circ} \mathrm{C}(f)$.

ограничение снимается, и рекристаллизация проходит однородно по всему объему.

Найти похожие результаты в литературных источниках не удалось в связи с малым количеством подобных исследований. Тем не менее работу [18] можно назвать близкой к данной по постановке эксперимента. В этом исследовании отжиг аморфных пленок $\mathrm{ZnO}$ проводился в течение часа при температурах 200, 400, 600 и $800^{\circ} \mathrm{C}$. При этом выраженной неоднородности в размерах кристаллитов обнаружено не было. Это несоответствие с результатами данного исследования можно объяснить тем, что в [18] рост зерен с повышением температуры отжига происходит за счет более интенсивного превращения аморфной фазы, а не коалесценции зерен. 


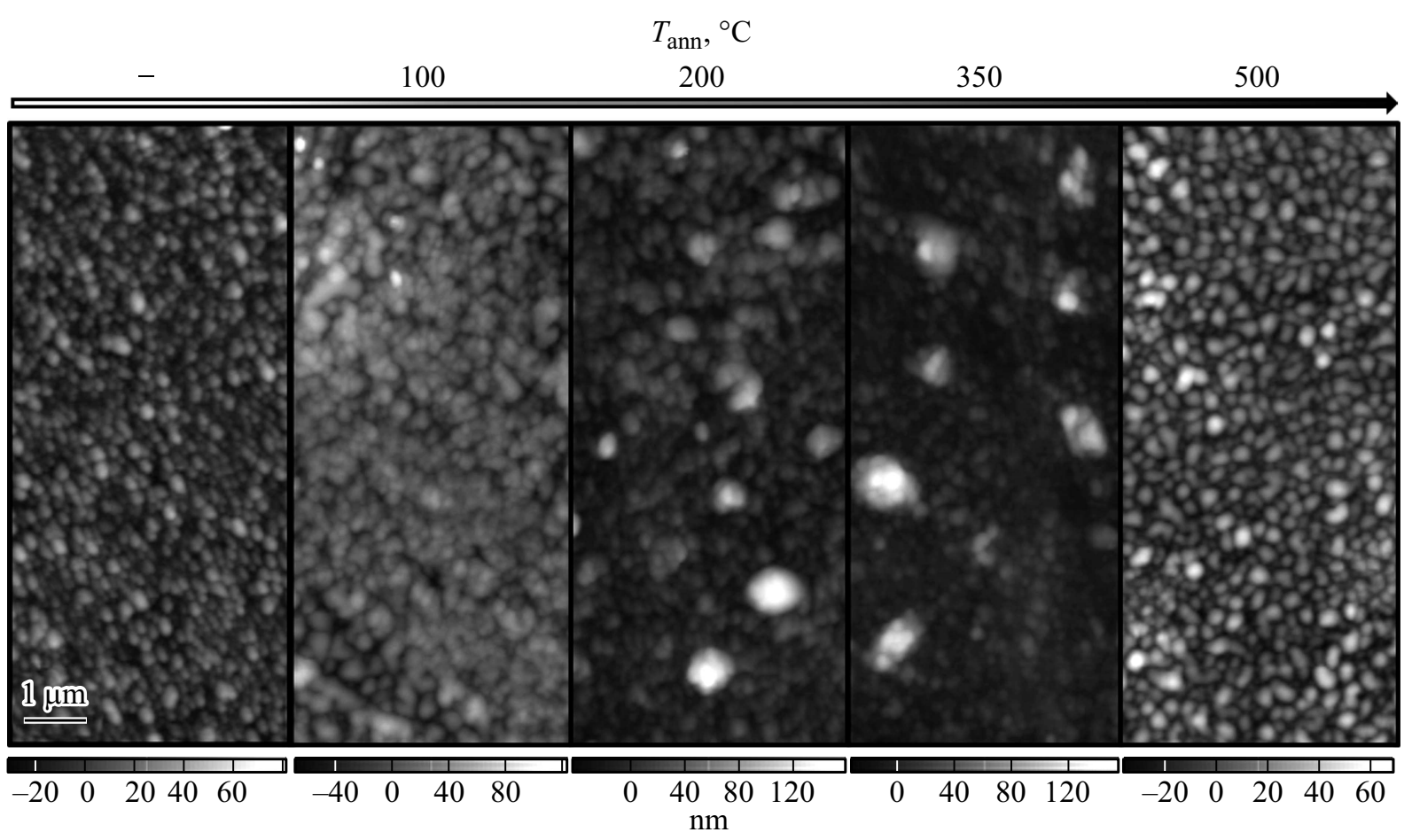

Рис. 2. АСМ-изображения пленок $\mathrm{ZnO}$ после отжига при различных температурах.

Из данного факта следует, что микроструктура пленки будет зависеть не только от температуры отжига, но и от начального состояния материала.

Из полученных результатов можно сделать вывод, что наиболее оптимальной температурой отжига для $\mathrm{ZnO}$ является $500^{\circ} \mathrm{C}$, при которой рекристаллизация происходит во всем объеме пленки, и существенных неоднородностей рельефа не возникает. С другой стороны, такой отжиг не привел к существенному изменению шероховатости, наблюдаемому в других работах [19]. Для неотожженной пленки, как и для образца с температурой отжига $500^{\circ} \mathrm{C}$, неоднородность по рельефу (параметр Root Mean Square) составляла $\sim 13$ нм. Для снижения этой величины в результате отжига необходимо усилить процесс рекристаллизации. С одной стороны, этого можно достичь повышением температуры, но в то же время схожий эффект должен проявиться, если пленка изначально будет характеризоваться лучшей кристалличностью. Данный подход был реализован в серии экспериментов с увеличенным расстоянием между подложкой и мишенью.

Известно, что при соударении ионов с мишенью возможно их отражение, в том числе упругое [20]. Отраженные ионы могут попадать на подложку и создавать в пленке дефекты. С одной стороны, это приводит к росту числа центров кристаллизации. С другой стороны, происходит нарушение кристаллической структуры, вследствие чего замедляются рекристаллизационные процессы во время отжига.

Интенсивность дефектообразования можно уменьшить с помощью повышения расстояния между мише-

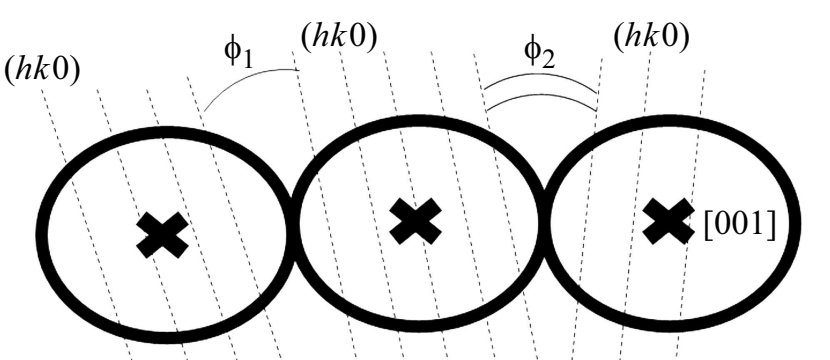

Рис. 3. Схематическое изображение различной ориентации кристаллитов $\mathrm{ZnO}$.

нью и подложкой, вследствие которого энергия отраженных ионов понижается за счет увеличения числа столкновений с атомами рабочего и остаточных газов, а также непосредственно с распыленными частицами. Однако при такой конфигурации уменьшается скорость напыления, поэтому время процесса необходимо увеличивать соответствующим образом. С другой стороны, само по себе снижение скорости также может способствовать уменьшению числа дефектов. Помимо изменения расстояния, $\mathrm{ZnO}$ напылялся на $\mathrm{Si}_{3} \mathrm{~N}_{4}$ (аморфный)/Si для лучшей демонстрации образования (001) текстуры посредством РД, т.е. без лишних пиков от окисла кремния. Пленка нитрида кремния имела толщину 50 нм и была получена методом плазмо-химического осаждения на подложку $\mathrm{Si}(111)$. В эксперименте с расстоянием мишень-подложка 45 мм напыление на 


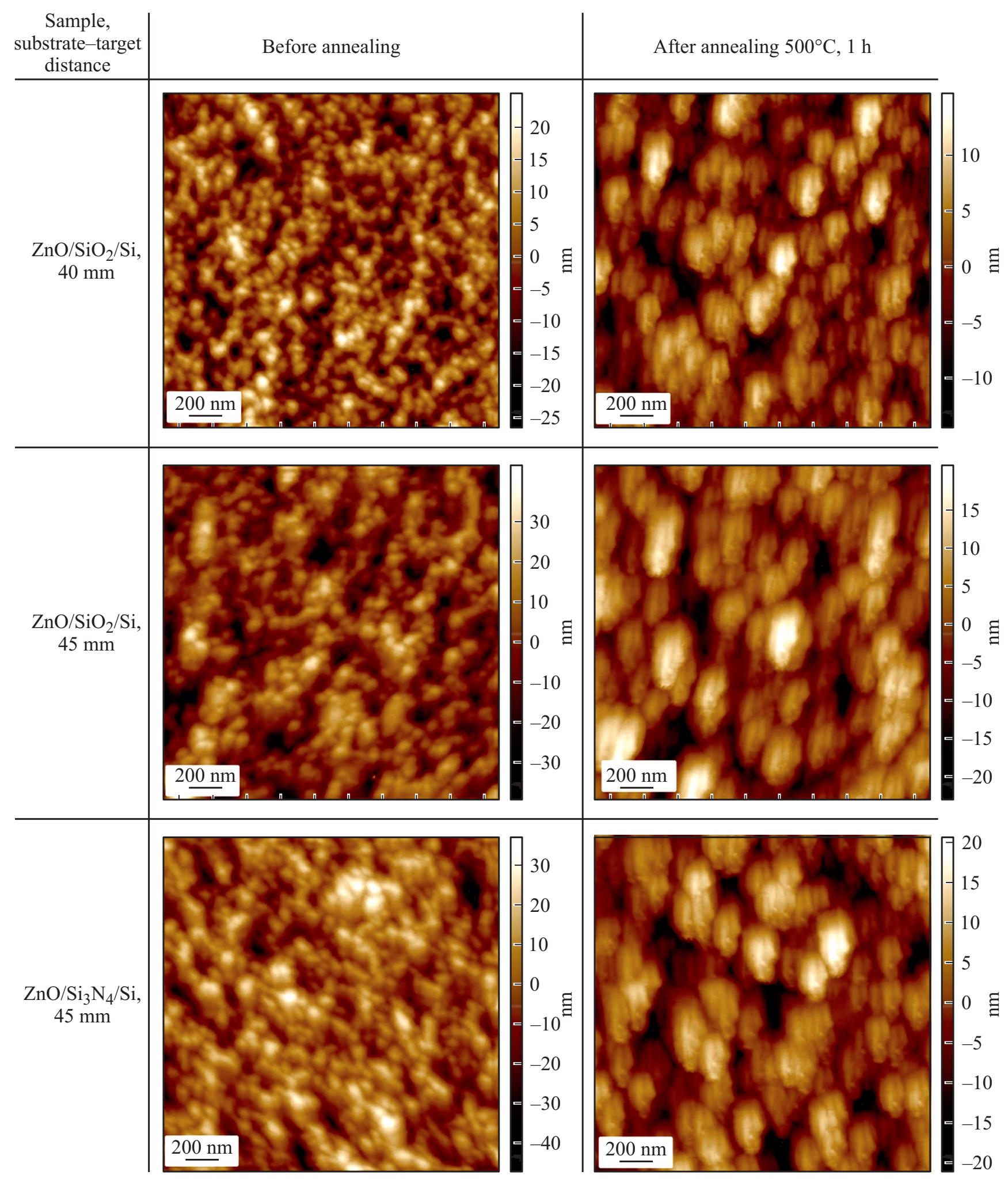

Рис. 4. АСМ-изображения поверхности пленок $\mathrm{ZnO}$, полученных при увеличенных расстояниях мишень-подложка.

подложки $\mathrm{Si}_{3} \mathrm{~N}_{4} / \mathrm{Si}$ и $\mathrm{SiO}_{2} / \mathrm{Si}$ проводилось одновременно, для корректного сравнения результатов. Для сохранения порядка эксперимента исследования АСМ образцов проводились сразу после нанесения пленок, а также после отжига при $500^{\circ} \mathrm{C}$, как наиболее оптимальной температуре (рис. 4). Морфология поверхности полученных пленок до отжига принципиально не отличается от начальных образцов. Однако рефлексы $\mathrm{ZnO}$ на РД 

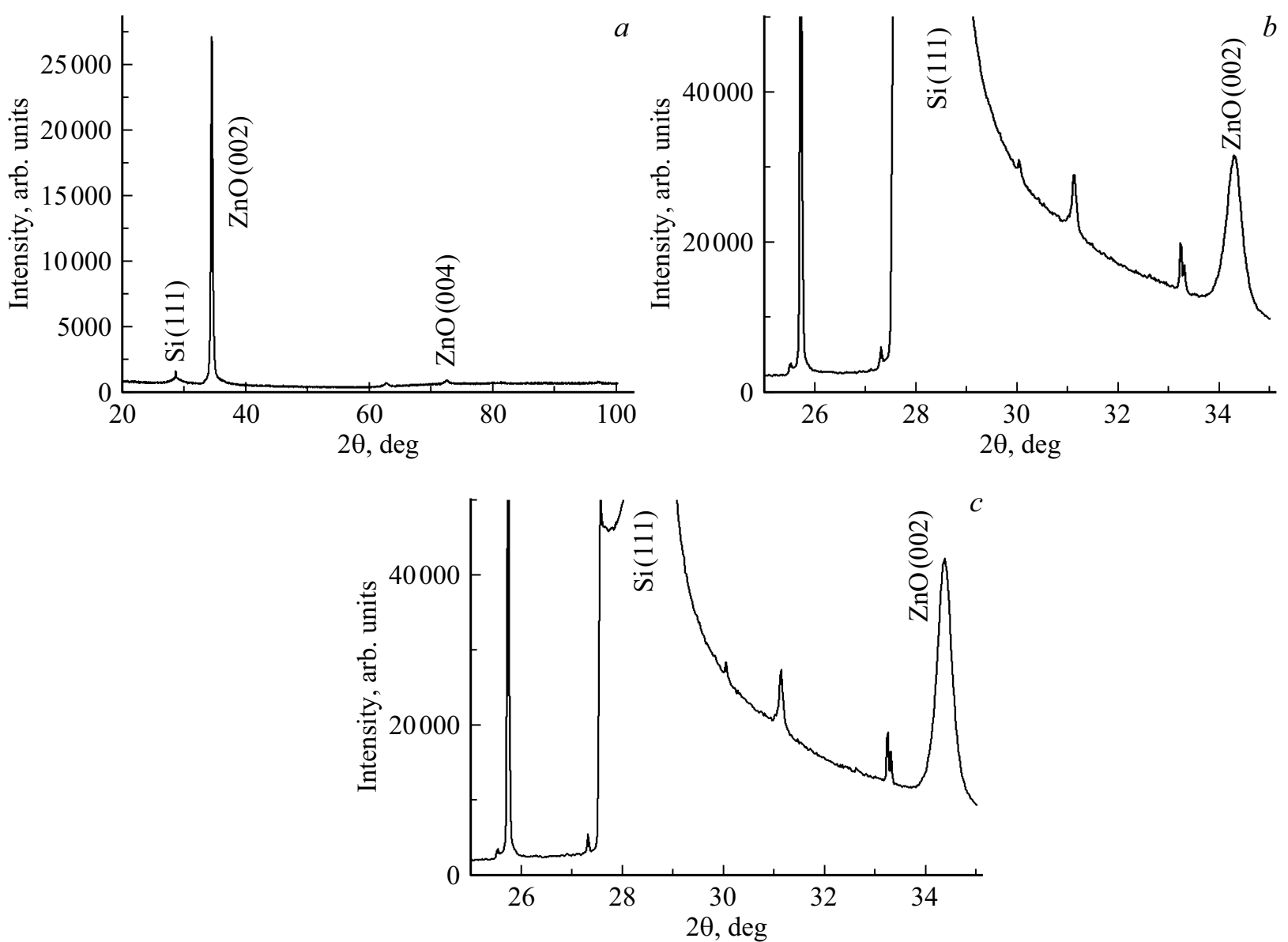

Рис. 5. Рентгеновские дифрактограммы пленок $\mathrm{ZnO}$, полученных при увеличенном расстоянии мишень-подложка (измерения до отжига): $a-\mathrm{ZnO} / \mathrm{Si}_{3} \mathrm{~N}_{4} / \mathrm{Si}, 45$ мм; $b-\mathrm{ZnO} / \mathrm{SiO}_{2} / \mathrm{Si}, 40$ мм; $c-\mathrm{ZnO} / \mathrm{SiO}_{2} / \mathrm{Si}, 45$ мм.

можно охарактеризовать как значительно более выраженные, что свидетельствует о лучшей кристалличности пленок (рис. 5, $a, b)$. Изменения, произошедшие в данных пленках после отжига при $500^{\circ} \mathrm{C}$, гораздо существеннее, чем при отжиге образца с расстоянием мишень-подложка 25 мм при той же температуре. Так, все зерна увеличились более чем в 2 раза (рис. 4), а шероховатость поверхности уменьшилась на $\sim 40 \%$ (см. таблицу).

Таким образом, в работе продемонстрировано как микроструктурные характеристики (размер зерен, шероховатость) пленок $\mathrm{ZnO}$ зависят от температуры отжига и начального состояния образцов. Образцы, полученные при повышенном расстоянии мишень-подложка и отожженные при $500^{\circ} \mathrm{C}$, представляются наиболее подходящими кандидатами на роль буферных слоев.

\section{4. Заключение}

Подтверждая результаты имеющихся литературных данных, на подложках из термически окисленных пластин кремния с ориентацией (111) методом ионнолучевого распыления мишени получены пленки $\mathrm{ZnO}$ с текстурой (001).

Показано, что микроструктура поверхности таких пленок $\mathrm{ZnO}$ изменяется после отжига на воздухе вследствие рекристаллизационных процессов. При этом в интервале температур от 200 до $350^{\circ} \mathrm{C}$ рекристаллизация локальна - наблюдается коалесценция небольшого числа зерен, расположенных неоднородно по поверхности. После отжига при $500^{\circ} \mathrm{C}$ зерна увеличиваются в размерах однородно по всей поверхности пленки. Интен-

Шероховатость поверхности пленок $\mathrm{ZnO}$, полученных при увеличенном расстоянии мишень-подложка

\begin{tabular}{c|c|c|c}
\hline Образец & $\begin{array}{c}\text { Расстояние } \\
\text { мишень-подложка, мм }\end{array}$ & Шероховатость, нм & $\begin{array}{c}\text { Шероховатость после } \\
\text { отжига при } 500^{\circ} \mathrm{C}, \text { нм }\end{array}$ \\
\hline $\mathrm{ZnO} / \mathrm{SiO}_{2} / \mathrm{Si}$ & 40 & 7.57 & 4.66 \\
$\mathrm{ZnO} / \mathrm{SiO}_{2} / \mathrm{Si}$ & 45 & 11.35 & 6.97 \\
$\mathrm{ZnO} / \mathrm{Si}_{3} \mathrm{~N}_{4} / \mathrm{Si}$ & 45 & 11.28 & 6.61
\end{tabular}


сивность такого роста зависит от начального состояния образца. В случае наличия большого числа дефектов, образованных в результате воздействия отраженных от мишени ионов рабочего газа, рост зерен после отжига незначителен. При снижении скорости нанесения и интенсивности ионной бомбардировки размеры кристаллитов после температурной обработки увеличиваются в несколько раз, а шероховатость поверхности уменьшается на $\sim 40 \%$.

\section{Конфликт интересов}

Авторы заявляют, что у них нет конфликта интересов.

\section{Список литературы}

[1] Т.В. Бланк, Ю.А. Гольдберг. ФТП, 37 (9), 1025 (2003).

[2] M. Matsuoka, M. Naoe. IEEE Trans. Magn., 25 (5), 1474 (1985).

[3] E. Lacroix, P. Gerard, G. Marest, M. Dupuy. J. Appl. Phys., 69 (8), 4770 (1991).

[4] А.М. Глезер, Н.А. Шурыгина. Аморфно-нанокристаллические сплавы (М., Физматлит, 2013).

[5] М.Н. Волочаев, Ю.Е. Калинин, М.А. Каширин, В.А. Макагонов, С.Ю. Панков, В.В. Бассараб. ФТП, 53 (11), 1505 (2019).

[6] D. Mendil, F. Challali, T. Touam, A. Chelouche, A.H. Souici, S. Ouhenia, D. Djouadi. J. Luminesc., 215, 116631 (2019).

[7] P.C. Dorsey, C. Vittoria. J. Magn. Magn. Mater., 137, 89 (1994).

[8] W. Yang, J. Liu, M. Liu, Y. Liu, N. Wang, G. Shen, Z. Liu, X. He, C. Zhang, L. Hu, Y. Fu. Superlat. Microstruct., 136, 106291 (2019).

[9] W. Yang, J. Liu, Z. Guan, Z. Liu, B. Chen, L. Zhao, Y. Li, X. Cao, X. He, C. Zhang, Q. Zeng, Y. Fu. Ceram. Int., 46, 6605 (2020).

[10] P. Murkute, H. Ghadi, S. Sreedhara, S. Chakrabarti. Superlat. Microstruct., 136, 106310 (2019).

[11] A. Kumar, M. Prasad, V. Janyani, R.P. Yadav. J. Electron. Mater., 48, 5693 (2019).

[12] Х.А. Абдуллин, Л.В. Гриценко, С.Е. Кумеков, А.А. Мархабаева, Е.И. Теруков. ФТП, 52 (2), 189 (2018).

[13] В.В. Ратников, Р.Н. Кютт, С.В. Иванов, М.П. Щеглов, A. Baar. ФТП, 44 (2), 265 (2010).

[14] N.V. Rumak, V.V. Khatko, V.N. Plotnikov. Phys. Status Solidi A, 86, 93 (1984).

[15] X. Zhang, Y. Duan, X. Dai, T. Li, Y. Xia, P. Zheng, H. Li, Y. Jiang. Appl. Surf. Sci., 504, 144437 (2020).

[16] A.A. Camacho-Berríosa, V.M. Pantojas, W. Otano. Thin Sol. Films, 692, 137641 (2019).

[17] X. Zhang, P. Wang, X. Liu, W. Zhang, Y. Zhong, H. Zhao, S. Shi, S. Jin, Y.W.R. Amarasinghe. Surf. Coat. Technol., 361, 123 (2019).

[18] J. Bruncko, A. Vincze, M. Netrvalova, P. Sutta, D. Hasko, M. Michalka. Thin Sol. Films, 520, 866 (2011).

[19] В.А. Смирнов, Р.В. Томинов, В.И. Авилов, Н.И. Алябьева, З.Е. Вакулов, Е.Г. Замбург, Д.А. Хахулин, О.А. Агеев. ФТП, 53 (1), 77 (2019).
[20] Л.В. Кожитов, С.Г. Емельянов, В.Г. Косушкин, С.С. Стрельченко, Ю.Н. Пархоменко, В.В. Козлов, С.Л. Кожитов. Технология материалов микро- и наноэлектроники (Курск, изд-во ЮЗГУ, 2012).

Редактор Г.А. Оганесян

\section{Structural peculiarities of textured zinc oxide films obtained by ion sputtering}

V.G. Kostishin ${ }^{1}$, A.Yu. Mironovich ${ }^{1}$, A.V. Timofeev' ${ }^{1}$, L.M. Isaev' ${ }^{1}$, R.I. Shakirzyanov'1, A.I. Ril'², A.A. Sergienko ${ }^{1}$

${ }^{1}$ National University of Science and technology „MISiS“, 119049 Moscow, Russia

${ }^{2}$ Kurnakov Institute of General and Inorganic Chemistry, Russian Academy of Sciences (IGIC RAS), 119991 Moscow, Russia

Abstract In this work, we studied textured $\mathrm{ZnO}$ films obtained by ion-beam deposition. $X$-ray diffraction patterns and micrographs of the surface revealed that asdeposited films have a polycrystalline structure. It was found that, after annealing of the samples in the temperature range from 200 to $500^{\circ} \mathrm{C}$, recrystallization occurs, leading to a change in the grain size and surface roughness. The dependence of the initial state of the film on the recrystallization intensity is also demonstrated. In films with an initially more perfect structure, temperature treatment at $500^{\circ} \mathrm{C}$ led to grain growth by more than 2 times and a decrease in roughness by $\sim 40 \%$. 